\title{
Comparative one-factor-at-a-time, response surface (statistical) and bench-scale bioreactor level optimization of thermoalkaline protease production from a psychrotrophic Pseudomonas putida SKG-1 isolate
}

Santosh K Singh', Sanjay K Singh', Vinayak R Tripathi', Sunil K Khare ${ }^{2}$ and Satyendra K Garg ${ }^{\text {** }}$

\begin{abstract}
Background: Production of alkaline protease from various bacterial strains using statistical methods is customary now-a-days. The present work is first attempt for the production optimization of a solvent stable thermoalkaline protease by a psychrotrophic Pseudomonas putida isolate using conventional, response surface methods, and fermentor level optimization.

Results: The pre-screening medium amended with optimized $(\mathrm{w} / \mathrm{v}) 1.0 \%$ glucose, $2.0 \%$ gelatin and $0.5 \%$ yeast extract, produced $278 \mathrm{U}$ protease $\mathrm{ml}^{-1}$ at $72 \mathrm{~h}$ incubation. Enzyme production increased to $431 \mathrm{Uml}^{-1} \mathrm{when} \mathrm{Mg}^{2+}$ $(0.01 \%, w / v)$ was supplemented. Optimization of physical factors further enhanced protease to $514 \mathrm{Uml}^{-1}$ at pH 9.0, $25^{\circ} \mathrm{C}$ and $200 \mathrm{rpm}$ within $60 \mathrm{~h}$. The combined effect of conventionally optimized variables (glucose, yeast extract, $\mathrm{MgSO}_{4}$ and $\mathrm{pH}$ ), thereafter predicted by response surface methodology yielded $617 \mathrm{U}$ protease $\mathrm{ml}^{-1}$ at glucose $1.25 \%(\mathrm{~W} / \mathrm{v})$, yeast extract $0.5 \%(\mathrm{w} / \mathrm{v}), \mathrm{MgSO}_{4} 0.01 \%(\mathrm{w} / \mathrm{v})$ and $\mathrm{pH}$ 8.8. Bench-scale bioreactor level optimization

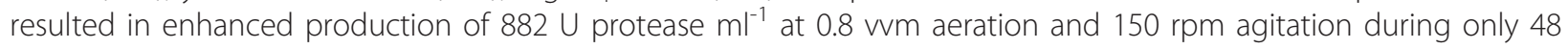
$\mathrm{h}$ incubation.
\end{abstract}

Conclusions: The optimization of fermentation variables using conventional, statistical approaches and aeration/ agitation at fermentor level resulted in $\sim 13.5$ folds increase (882 $\left.\mathrm{Um}^{-1}\right)$ in protease production compared to unoptimized conditions $\left(65 \mathrm{Uml}^{-1}\right)$. This is the highest level of thermoalkaline protease reported so far by any psychrotrophic bacterium.

\section{Background}

Proteases are one of the most exploited industrial groups of enzymes accounting for nearly $60 \%$ of the total worldwide sale of enzymes [1]. In order to meet the growing demand of proteases with cost effectivity, scaling-up of the industrial process is imperative. Joo et al. [2] opined that $30-40 \%$ cost of industrial enzymes depends on the growth medium. Major nutritional factors affecting protease production are sources of carbon, nitrogen, growth factors and metal ions [1]. Besides, physical factors such

\footnotetext{
* Correspondence: sk_garg001@yahoo.com

${ }^{1}$ Center of Excellence, Department of Microbiology, Dr. Ram Manohar Lohia

Avadh University, Faizabad-224001, UP, India

Full list of author information is available at the end of the article
}

as temperature, $\mathrm{pH}$, aeration/agitation and incubation time also significantly affect the protease production [3]. Therefore, optimization of nutritional and physical parameters for maximum enzyme production is of utmost importance for making the industrial process cost-effective and economically viable.

In conventional 'one-variable-at-a-time' approach, the nutritional/cultural factors are optimized by changing one factor at a time, and keeping other variables constant. This approach is simplest to implement, and primarily helps in selection of significant parameters affecting the enzyme yield. However, this method is not only time restrictive, but also ignores the combined interaction(s) among various physical and nutritional parameters [4]. Conversely,

(C) 2011 Singh et al; licensee BioMed Central Ltd. This is an Open Access article distributed under the terms of the Creative Commons 
the statistical response surface methodology (RSM) is a useful model for simultaneously studying the effect of several factors influencing the process of enzyme production. This also reduces the number of experiments required in growth medium optimization. Use of factorial designs and regression analyses for generating empirical models makes RSM a good statistical tool [5]. To analyze the effect of various factors in better way, a number of statistical approaches with response surface methodology are attempted for the optimization of enzyme production.

Scaling-up of protease production is also governed by aeration, agitation and dissolved oxygen tension (DOT) of fermenting medium. Agitation and aeration processes are important variables in aerobic fermentation, as oxygen availability and its proper distribution in the fermenting medium is regulatory for protease production. At flask level fermentation process, only agitation can be regulated; however, it results in limited aeration, and hence reduced protease yield. This could be due to less availability of dissolved oxygen (DO), which adversely affects the cell growth and enzyme yield [6]. Hence, bioreactors are preferred over flask level microbial fermentation for optimization of aeration, agitation and dissolved oxygen tension. Although, bioreactors provide efficient oxygen distribution in the fermenting broth, sometimes increased shear can reduce the protease yield. So, a proper ratio of agitation and aeration is required for maximization of protease production [7]. Therefore, optimal conditions for expression of high activity must be first determined in laboratory-scale followed by pilot- and industrial-level fermentors [8].

Keeping the above in view, the present study is an attempt to enhance protease production through optimization of nutritional/physical parameters by conventional (one-variable-at-a-time) and statistical approach (RSM) at shake flask level. Further, the effect of agitation, aeration and dissolved oxygen tension (DOT) on production of a psychro-thermo-alkalistable protease from Pseudomonas putida SKG-1 in bench-scale fermentor (under RSM optimized nutritional and cultural parameters) was also envisaged.

\section{Materials and Methods}

\section{Microorganism and protease production}

Pseudomonas putida SKG-1 (MTCC 10510) was isolated in our laboratory. This solvent and heavy metal tolerant strain is capable of producing solvent-, psychro-, thermo, alkali-stable protease [9]. The pure culture was maintained over nutrient agar slants $\left(\mathrm{pH} \mathrm{7.0)}\right.$ at $4^{\circ} \mathrm{C}$.

For protease production, $250 \mathrm{ml}$ sterile modified GYE (MGYE) broth [10] of pH 9.0 was taken in $500 \mathrm{ml}$ Erlenmeyer flask, inoculated with $2 \%(\mathrm{v} / \mathrm{v})$ mother culture of $0.8 \mathrm{OD}\left(\mathrm{A}_{660} ; 1 \mathrm{~cm}\right.$ cuvette $)$ containing $2.8 \times 10^{8}$ colony forming units (cfu) $\mathrm{ml}^{-1}$ and incubated at $25^{\circ} \mathrm{C}$ in shaker incubator $(150 \mathrm{rpm})$. The fermenting broth $(5.0$ $\mathrm{ml}$ ) was periodically drawn aseptically, and growth was assessed by turbidity measurement at $660 \mathrm{~nm}$. Each sample was then centrifuged at $12,000 \mathrm{rpm}\left(4^{\circ} \mathrm{C}\right)$ for 10 min, and cell-free supernatant was used for protease assay.

\section{Enzyme assay}

The protease activity was assayed by casein digestion method of Shimogaki et al. [11] at $40^{\circ} \mathrm{C}$ and $\mathrm{pH} 9.5$ (sodium carbonate-bicarbonate buffer). One unit of protease activity is defined as the amount of enzyme required to liberate $1 \mu \mathrm{g}$ of tyrosine $\mathrm{min}^{-1}$.

\section{Optimization of nutritional and physical parameters}

In the conventional scaling-up approach, various nutritional and physical parameters were optimized by maintaining all factors at a constant level in the basal medium, except the one under study. Each subsequent factor was examined after taking into account the previously optimized factor(s). Among carbon sources fructose, xylose, lactose, sucrose, soluble starch, maltose, glycerol and carboxymethyl cellulose (CMC) were supplemented individually by replacing glucose in the basal medium. All sugars were autoclaved separately at $10 \mathrm{psi}$ for $20 \mathrm{~min}$, and added at $1.0 \%(\mathrm{w} / \mathrm{v})$ level. For the effect of different nitrogen sources, peptone plus yeast extract in MGYE broth were replaced individually by gelatin, urea, casein, casamino acid, beef extract, yeast extract, tryptone, sodium nitrate, ammonium nitrate and ammonium sulfate at $1.0 \%(\mathrm{w} / \mathrm{v})$ level. Combination of each nitrogen source with $0.5 \%(\mathrm{w} / \mathrm{v})$ yeast extract (YE) was also attempted. After optimization of carbon and nitrogen sources along with their concentrations, varied levels of yeast extract $(0.1-0.7 \% \mathrm{w} / \mathrm{v})$ were also studied to optimize its dose. Metal cations $(0.01 \% \mathrm{w} / \mathrm{v})$ studied to enhance protease yield were: $\mathrm{Ca}^{2+}\left(\mathrm{CaCl}_{2}\right), \mathrm{Cu}^{2+}$ $\left(\mathrm{CuSO}_{4}\right), \mathrm{Mg}^{2+}\left(\mathrm{MgSO}_{4}\right), \mathrm{Mn}^{2+}\left(\mathrm{MnSO}_{4}\right), \mathrm{Fe}^{2+}\left(\mathrm{FeCl}_{2}\right)$, $\mathrm{Zn}^{2+}\left(\mathrm{ZnSO}_{4}\right)$ and combination of $\mathrm{Ca}^{2+}+\mathrm{Mg}^{2+}$ ions. The dose of best metal ion was optimized by its supplementation at $0.005-0.05 \%(\mathrm{w} / \mathrm{v})$ concentrations. Initial $\mathrm{pH}$ of the medium (7.0-10.0), shaking speed (0-250 $\mathrm{rpm})$, temperature $\left(10-40^{\circ} \mathrm{C}\right)$ and time of incubation $(0$ $72 \mathrm{~h}$ ) were the physical parameters studied for their effect on bacterial growth and protease production.

\section{Statistical optimization of factors affecting protease production by RSM}

Box-Behnken design (Design Expert 8.0.5) was adapted to define the nature of response surface in the experimental region, and to identify the optimal level of four most significant conventionally optimized variables, viz., glucose (A), yeast extract (B), $\mathrm{MgSO}_{4}(\mathrm{C})$ and $\mathrm{pH}(\mathrm{D})$. The experimental design was generated and analyzed by 
using statistical software Design Expert-8.0.5. The effect of each variable on enzyme production was studied at three different levels $(-1,0$ and +1$)$ with minimum, central and maximum value (Table 1 ), and thirty (30) experimental setups were obtained (Table 2).

A second order polynomial equation was used for the analysis of protease production, and the data were fitted in the equation by multiple regression procedure. This resulted in an empirical model. The model equation for analysis is as under:

$$
\mathrm{Y}=\beta_{0}+\sum \beta_{\mathrm{n}} \mathrm{X}_{\mathrm{n}}+\sum \beta_{\mathrm{nn}} \mathrm{X}_{\mathrm{n}}^{2}+\sum \beta_{\mathrm{nm}} \mathrm{X}_{\mathrm{n}} \mathrm{X}_{\mathrm{m}}
$$

Where, $\mathrm{Y}$ is the predicted response, $\beta_{\mathrm{o}}$ offset term, $\beta_{\mathrm{n}}$ liner coefficient, $\beta_{\mathrm{nn}}$ squared coefficient, $\beta_{\mathrm{nm}}$ interaction coefficient, $X_{n} n^{\text {th }}$ independent variable, $X_{n}{ }^{2}$ squared effect and $\mathrm{X}_{\mathrm{n}} \mathrm{X}_{\mathrm{m}}$ interaction effects.

For four variable systems, the model equation is as follows:

$$
\begin{aligned}
\mathrm{Y} & =\beta_{0}+\beta_{1} \mathrm{~A}+\beta_{2} \mathrm{~B}+\beta_{3} \mathrm{C}+\beta_{4} \mathrm{D}+\beta_{11} \mathrm{~A}^{2}+\beta_{22} \mathrm{~B}^{2}+\beta_{33} \mathrm{C}^{2}+\beta_{44} \mathrm{D}^{2} \\
& +\beta_{12} \mathrm{AB}+\beta_{13} \mathrm{AC}+\beta_{14} \mathrm{AD}+\beta_{23} \mathrm{BC}+\beta_{24} \mathrm{BD}+\beta_{34} \mathrm{CD}
\end{aligned}
$$

Design-Expert software was used to obtain the coefficient of equation (2) based on data provided in Table 2. Analysis of variance (ANOVA) was used to analyze the responses under different combinations as defined by the design (Table 3).

\section{Bench-scale bioreactor level optimization Effect of aeration}

Fermentation was performed in a stirred tank bioreactor (Bioflo 110, New Brunswick Scientific Co. Inc. Edison, NJ, USA) of 3 liter capacity. The fermentor was equipped with direct drive dual Rushton style impeller, PID temperature and agitation control, probes and controller for $\mathrm{pH}$ and DO. For protease production, fermentation was carried out in one liter GGY broth under conventional and RSM optimized nutritional (glucose $1.25 \%$, gelatin $2 \%$, yeast extract $0.5 \%, \mathrm{Mg}^{2+} 0.01 \%$ ) and cultural $\left(\mathrm{pH} 8.8,25^{\circ} \mathrm{C}, 200 \mathrm{rpm}\right)$ conditions. The medium was inoculated $(2 \%, \mathrm{v} / \mathrm{v})$ with the mother culture of strain SKG-1 (0.8 OD, $\mathrm{A}_{660} ; 1 \mathrm{~cm}$ cuvette) containing $2.8 \times 10^{8} \mathrm{cfu} \mathrm{ml}^{-1}$. The aeration of culture broth was

Table 1 Experimental range and the levels of four independent variables employed in RSM in terms of actual and coded factors

\begin{tabular}{cccc}
\hline Variables & \multicolumn{3}{c}{ Levels } \\
\cline { 2 - 4 } & $\mathbf{- 1}$ & $\mathbf{0}$ & $\mathbf{+ 1}$ \\
\hline Glucose $(\%, w / v)$ & 0.75 & 1.00 & 1.25 \\
Yeast extract $(\%, w / v)$ & 0.30 & 0.50 & 0.70 \\
$\mathrm{MgSO}_{4}(\%, w / v)$ & 0.0075 & 0.0100 & 0.0125 \\
$\mathrm{pH}$ & 8.80 & 9.00 & 9.20 \\
\hline
\end{tabular}

effected at different rates (0-1.5 vvm), and samples (5.0 $\mathrm{ml}$ ) were drawn periodically at $12 \mathrm{~h}$ intervals. The bacterial growth was assessed by turbidity measurement at $660 \mathrm{~nm}$. The sample broth was then centrifuged at $12,000 \mathrm{rpm}\left(4^{\circ} \mathrm{C}\right)$ for $10 \mathrm{~min}$, and cell-free supernatant was used to assay the protease activity. Change in DOT during the course of fermentation was also recorded throughout the incubation period.

\section{Effect of agitation at optimized aeration}

The growth and protease production was further studied by varying the agitation speed from 100 to $250 \mathrm{rpm}$ at optimized aeration rate. Other experimental conditions remained the same.

\section{Statistical analysis}

Each set of experiment was performed thrice, and all values presented here are average of three independent experiments. The standard deviation for each value is $\leq$ $5 \%$.

\section{Results and Discussion Protease production}

The strain SKG-1 exhibited typical sigmoidal growth curve in modified GYE broth (Figure 1). After a steep exponential growth, the onset of stationary phase was at $60^{\text {th }} \mathrm{h}$ onwards, and attained maximum growth and protease production at 66 and $72 \mathrm{~h}$, respectively. The enzyme production initiated at $6^{\text {th }} \mathrm{h}$ of bacterial growth with maximum $65 \mathrm{Uml}^{-1}$ during stationary phase at 72 $\mathrm{h}$ incubation, which thereafter decreased with time (Figure 1). Maximum enzyme production during stationary growth phase is in accordance with the findings of other researchers [2,10]. Pseudomonas aeruginosa PseA strain exhibited slow growth up to $12 \mathrm{~h}$, exponential growth up to $48 \mathrm{~h}$, followed by a stationary phase. The protease secretion corresponded with the growth response, and reached maximum during the late exponential/early stationary phase [3].

\section{Optimization of nutritional and physical parameters Carbon source}

Maximum protease was produced with soluble starch $\left(71 \mathrm{Uml}^{-1}\right)$ followed by glucose $\left(65 \mathrm{Uml}^{-1}\right)$ at $72 \mathrm{~h}$ incubation. Other carbon sources produced less enzyme in the following order $\left(\mathrm{Uml}^{-1}\right)$ : fructose (54) $>$ maltose (49) $>$ sucrose $(43)>$ glycerol $(40)>$ xylose $(36)>$ lactose (33) > carboxymethyl cellulose (27) (Table 4). Although maximum enzyme was produced by soluble starch, glucose (second best) was selected for further studies due to cost consideration. Further, maximum protease $(67$ $\mathrm{Uml}^{-1}$ ) was produced at $1.5 \%$ glucose level though, it was merely $3 \%$ more $\left(65 \mathrm{Uml}^{-1}\right)$ than that produced at $1.0 \%(\mathrm{w} / \mathrm{v})$ glucose concentration. Therefore, $1.0 \%(\mathrm{w} / \mathrm{v})$ glucose was selected as the suitable concentration for 
Table 2 Experimental designs used in RSM studies by using four independent variables with six centre points showing observed and predicted values of protease production

\begin{tabular}{|c|c|c|c|c|c|c|}
\hline $\begin{array}{l}\text { Standard } \\
\text { Order }\end{array}$ & $\begin{array}{c}\text { Factor A } \\
\text { (Glucose \%, } \\
\text { w/v) }\end{array}$ & $\begin{array}{c}\text { Factor B } \\
\text { (Yeast extract \%, } \\
\text { w/v) }\end{array}$ & $\begin{array}{c}\text { Factor } \mathrm{C}\left(\mathrm{MgSO}_{4} \%,\right. \\
\mathrm{w} / \mathrm{v})\end{array}$ & $\begin{array}{l}\text { Factor D } \\
(\mathrm{pH})\end{array}$ & $\begin{array}{l}\text { Observed response } \\
\left(\mathrm{Uml}^{-1}\right)\end{array}$ & $\begin{array}{l}\text { Predicted response } \\
\left(\quad\left(U \mathrm{ml}^{-1}\right)\right.\end{array}$ \\
\hline 1 & 0.75 & 0.30 & 0.0100 & 9.00 & 419 & 418.13 \\
\hline 2 & 1.25 & 0.30 & 0.0100 & 9.00 & 457 & 455.63 \\
\hline 3 & 0.75 & 0.70 & 0.0100 & 9.00 & 449 & 451.13 \\
\hline 4 & 1.25 & 0.70 & 0.0100 & 9.00 & 482 & 483.63 \\
\hline 5 & 1.00 & 0.50 & 0.0075 & 8.80 & 524 & 562.46 \\
\hline 6 & 1.00 & 0.50 & 0.0125 & 8.80 & 540 & 541.96 \\
\hline 7 & 1.00 & 0.50 & 0.0075 & 9.20 & 372 & 370.79 \\
\hline 8 & 1.00 & 0.50 & 0.0125 & 9.20 & 396 & 394.29 \\
\hline 9 & 0.75 & 0.50 & 0.0100 & 8.80 & 561 & 561.58 \\
\hline 10 & 1.25 & 0.50 & 0.0100 & 8.80 & 617 & 612.58 \\
\hline 11 & 0.75 & 0.50 & 0.0100 & 9.20 & 426 & 425.92 \\
\hline 12 & 1.25 & 0.50 & 0.0100 & 9.20 & 447 & 444.92 \\
\hline 13 & 1.00 & 0.30 & 0.0075 & 9.20 & 369 & 365.25 \\
\hline 14 & 1.00 & 0.70 & 0.0075 & 9.00 & 415 & 413.75 \\
\hline 15 & 1.00 & 0.30 & 0.0125 & 9.00 & 406 & 402.75 \\
\hline 16 & 1.00 & 0.70 & 0.0125 & 9.00 & 416 & 415.25 \\
\hline 17 & 0.75 & 0.50 & 0.0075 & 9.00 & 446 & 446.63 \\
\hline 18 & 1.25 & 0.50 & 0.0075 & 9.00 & 479 & 482.13 \\
\hline 19 & 0.75 & 0.50 & 0.0125 & 9.00 & 466 & 466.63 \\
\hline 20 & 1.00 & 0.50 & 0.0125 & 9.00 & 498 & 501.13 \\
\hline 21 & 1.00 & 0.30 & 0.0125 & 8.80 & 509 & 512.96 \\
\hline 22 & 1.00 & 0.70 & 0.0100 & 8.80 & 513 & 511.46 \\
\hline 23 & 1.00 & 0.30 & 0.0100 & 9.20 & 324 & 329.29 \\
\hline 24 & 1.00 & 0.70 & 0.0100 & 9.20 & 392 & 391.79 \\
\hline 25 & 1.00 & 0.50 & 0.0100 & 9.00 & 514 & 514 \\
\hline 26 & 1.00 & 0.50 & 0.0100 & 9.00 & 514 & 514 \\
\hline 27 & 1.00 & 0.50 & 0.0100 & 9.00 & 514 & 514 \\
\hline 28 & 1.00 & 0.50 & 0.0100 & 9.00 & 514 & 514 \\
\hline 29 & 1.00 & 0.50 & 0.0100 & 9.00 & 514 & 514 \\
\hline 30 & 1.00 & 0.50 & 0.0100 & 9.00 & 514 & 514 \\
\hline
\end{tabular}

further optimization of protease production (Table 4). An inducible effect of glucose on protease production was reported by other researchers also $[1,12]$. Gupta and Khare [3] reported that Pseudomonas aeruginosa PseA produced maximum protease by $\mathrm{CM}$-cellulose as the best carbon source followed by glycerol, sucrose, maltose and fructose. However, CM-cellulose was not selected for further studies rather glycerol, the second best carbon source was preferred due to economic reasons.

\section{Nitrogen source}

Each organic and inorganic nitrogen source employed supported bacterial growth and protease production. However, maximum enzyme was produced with gelatin plus yeast extract (Table 4). Other nitrogen sources either alone or in combination with yeast extract produced lesser enzyme. In general, protease production was more with organic as compared to inorganic nitrogen sources (Table 4). Although, yeast extract in combination with inorganic nitrogen sources marginally increased enzyme production, it was meagre compared to complex nitrogen sources. The reduced protease production in the presence of inorganic nitrogen sources is in agreement with the findings of other researchers $[3,13,14]$. Complex nitrogen sources are generally required for protease production; however, the requirement of specific nitrogen source varies from organism to organism [15]. Several researchers have reported maximum protease production in the presence of complex nitrogen sources $[3,16]$. In the present study, gelatin (best nitrogen source) at $2 \%(\mathrm{w} / \mathrm{v})$ plus yeast extract $(0.5 \%, \mathrm{w} / \mathrm{v})$ were most suitable for maximum $\left(278 \mathrm{Uml}^{-}\right.$ $\left.{ }^{1}\right)$ protease production (Tables 4 and 5). Gupta and Khare [3] found $0.6 \%(\mathrm{w} / \mathrm{v})$ yeast extract most suitable for maximum protease production by $P$. aeruginosa PseA. Yeast extract not only serves as a nitrogen source, 
Table 3 ANOVA for Response Surface Quadratic Model

\begin{tabular}{|c|c|c|c|c|c|}
\hline Source & Sum of squares & df & Mean square & $F$-value & p-value \\
\hline Model & $1.205 E+005$ & 14 & 8609.99 & 820.46 & $<0.0001$ \\
\hline A-Glucose & 3675.00 & 1 & 3675.00 & 350.20 & $<0.0001$ \\
\hline B-Yeast extract & 2790.75 & 1 & 2790.75 & 265.94 & $<0.0001$ \\
\hline $\mathrm{C}-\mathrm{MgSO}_{4}$ & 1140.75 & 1 & 1140.75 & 108.70 & $<0.0001$ \\
\hline D-pH & 69008.33 & 1 & 69008.33 & 6575.95 & $<0.0001$ \\
\hline$A B$ & 6.25 & 1 & 6.25 & 0.60 & 0.4531 \\
\hline$A C$ & 0.25 & 1 & 0.25 & 0.024 & 0.8795 \\
\hline$A D$ & 256.00 & 1 & 256.00 & 24.39 & 0.0002 \\
\hline$B C$ & 324.00 & 1 & 324.00 & 30.87 & $<0.0001$ \\
\hline $\mathrm{BD}$ & 1024.00 & 1 & 1024.00 & 97.58 & $<0.0001$ \\
\hline$C D$ & 16.00 & 1 & 16.00 & 1.52 & 0.2372 \\
\hline$A^{2}$ & 274.05 & 1 & 274.05 & 26.12 & 0.0002 \\
\hline$B^{2}$ & 30325.24 & 1 & 30325.24 & 2889.76 & $<0.0001$ \\
\hline$c^{2}$ & 13950.10 & 1 & 13950.10 & 1329.33 & $<0.0001$ \\
\hline$D^{2}$ & 555.00 & 1 & 555.00 & 52.89 & $<0.0001$ \\
\hline Residual & 146.92 & 14 & 10.49 & & \\
\hline Lack of fit & 146.92 & 10 & 14.69 & & \\
\hline Pure error & 0.000 & 4 & 0.000 & & \\
\hline Cor total & $1.205 E+005$ & 28 & & & \\
\hline Standard deviation & \multicolumn{2}{|l|}{3.24} & \multicolumn{2}{|c|}{ R-squared } & 0.9988 \\
\hline Mean & \multicolumn{2}{|l|}{465.38} & \multicolumn{2}{|c|}{ Adjusted R-squared } & 0.9976 \\
\hline Coefficient of variation (C.V.\%) & \multicolumn{2}{|l|}{0.70} & \multicolumn{2}{|c|}{ Predicted R-squared } & 0.9930 \\
\hline PRESS & \multicolumn{2}{|l|}{846.24} & \multicolumn{2}{|c|}{ Adequate precision } & 121.595 \\
\hline
\end{tabular}

but also provides vitamins for promoting bacterial growth and enzyme production [17].

\section{Metal ions}

Table 5 reveals that $\mathrm{Mg}^{2+}$ and $\mathrm{Ca}^{2+}$ ions individually and in combination enhanced the protease production. However, maximum enzyme (431 $\mathrm{Uml}^{-1}$ ) was produced with $\mathrm{Mg}^{2+}$ ions alone, and was therefore, selected for further studies. Other metal ions $\left(\mathrm{Cu}^{2+}, \mathrm{Fe}^{2+}, \mathrm{Zn}^{2+}, \mathrm{Mn}^{2+}\right)$ reduced protease production (Table 5). Among different

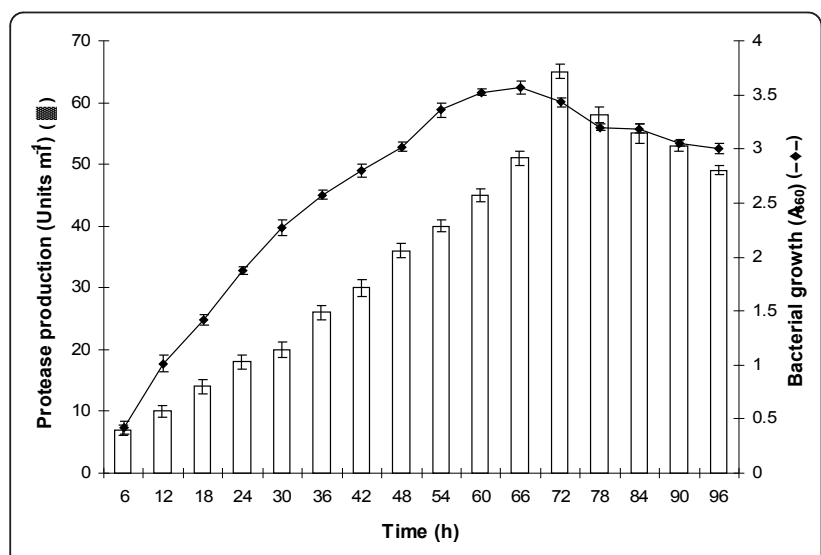

Figure 1 Bacterial growth and extracellular protease production in modified GYE broth (pH 9.0) at $25^{\circ} \mathrm{C}$ and 150 rpm during $96 \mathrm{~h}$ incubation. levels of $\mathrm{Mg}^{2+}(0.005-0.05 \% \mathrm{w} / \mathrm{v})$ employed, $0.01 \%$ (w/v) was most effective. Any deviation in $\mathrm{Mg}^{2+}$ concentration from optimum $0.01 \%(\mathrm{w} / \mathrm{v})$ adversely affected protease yield (Table 5). Our results are in accordance with the findings of other researchers, who also reported $\mathrm{Mg}^{2+}$ as the best metal ion supplement for protease production and bacterial growth [18]. Rahman et al. [17] also reported enhanced protease production in the presence of $\mathrm{Mg}^{2+}$ by $P$. aeruginosa strain $\mathrm{K}$. The stimulating effect of $\mathrm{CaCl}_{2}$ was reported by Mabrouk et al. [19]. They attributed this effect to the stabilizing nature of $\mathrm{CaCl}_{2}$ on alkaline protease.

Initial $\mathrm{pH}$

The organism was able to grow in the selected $\mathrm{pH}$ range (7.0-10.0), but protease production was restricted to $\mathrm{pH}$ range 7.5-9.5 only. At $\mathrm{pH} 9.0$, maximum protease $\left(431 \mathrm{Uml}^{-1}\right)$ was produced under optimized nutritional conditions. Any deviation in $\mathrm{pH}$ from optimum 9.0 adversely affected the bacterial growth and enzyme production. At pH 7.0 and 10.0, protease production was not detected (Table 5). The alkaline $\mathrm{pH}$ optimum reveals alkaliphilic nature of strain SKG-1. Joshi et al. [20] also reported maximum protease yield at $\mathrm{pH} 9.0$ by $B$. cereus isolate. Bacillus sp. strain APP1 was able to grow well in $\mathrm{pH}$ range $5.0-12.0$, but produced protease maximally at $\mathrm{pH} 9.0$ [21]. Other researchers have reported maximum alkaline protease production at $\mathrm{pH}$ $7.0-7.5$ also $[3,13,22]$ 
Table 4 Effect of different carbon and nitrogen sources on protease (Uml ${ }^{-1}$ ) production (A) and growth (B) of Pseudomonas putida SKG-1 at pH 9.0, $25^{\circ} \mathrm{C}$ and $150 \mathrm{rpm}$ during $96 \mathrm{~h}$ incubation

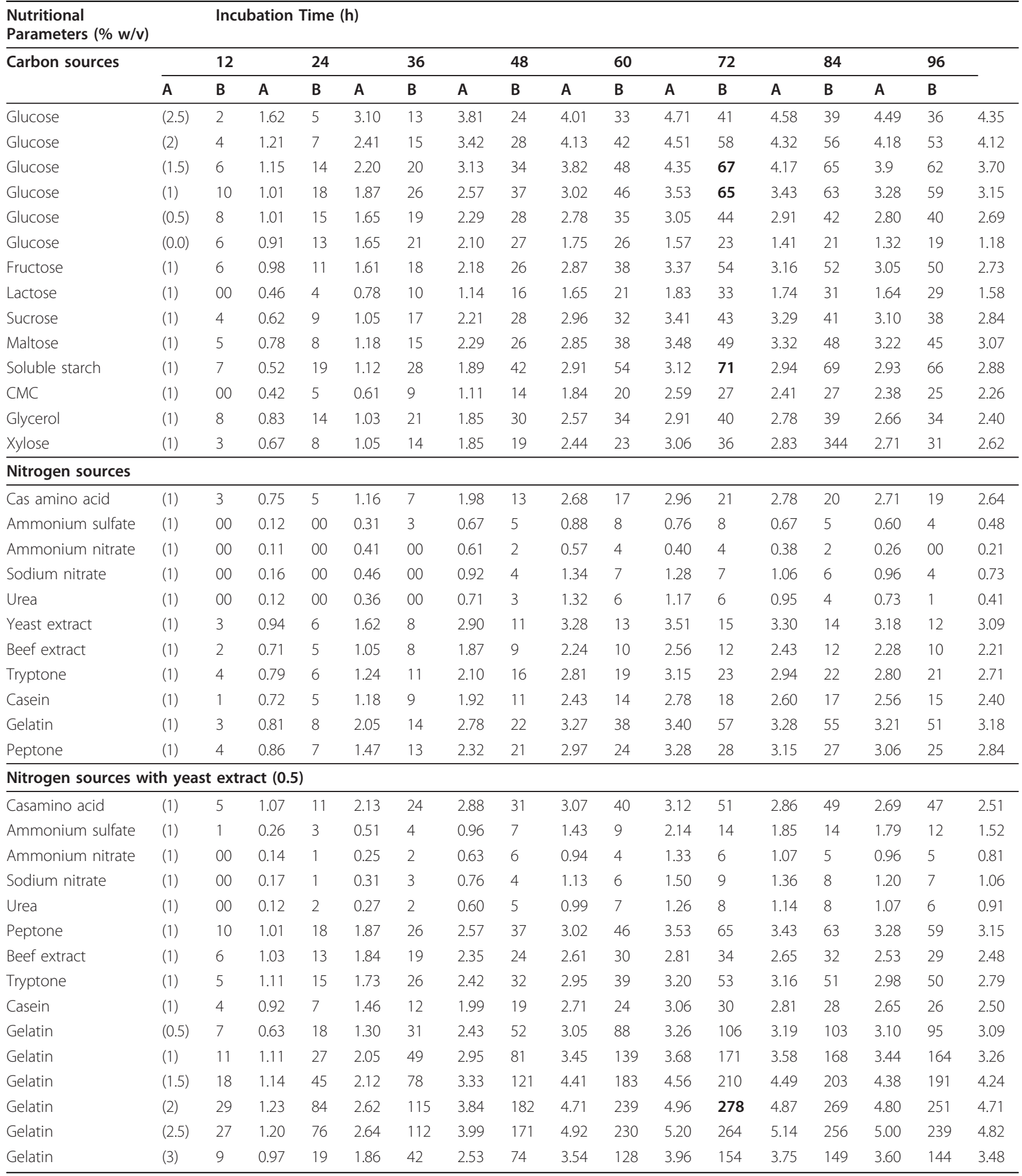

\section{Agitation}

Shaking of cultures significantly affected protease production, which was maximum $\left(514 \mathrm{Uml}^{-1}\right)$ at $200 \mathrm{rpm}$. Any change in agitation speed decreased enzyme production, and produced 97, 283, 431 and $49 \mathrm{U}$ protease $\mathrm{ml}^{-1}$ at 50,100, 150 and $250 \mathrm{rpm}$, respectively (Table 5). Presumably at $200 \mathrm{rpm}$ agitation, the aeration of culture broth increased optimally, which enhanced 
Table 5 Effect of yeast extract, metal ions and physical factors on protease $\left(\mathrm{Uml}^{-1}\right)$ production $(\mathrm{A})$ and bacterial growth (B) at $\mathrm{pH} 9.0,25^{\circ} \mathrm{C}$ and $150 \mathrm{rpm}$ during $96 \mathrm{~h}$ incubation

\begin{tabular}{|c|c|c|c|c|c|c|c|c|c|c|c|c|c|c|c|c|c|}
\hline \multicolumn{2}{|c|}{$\begin{array}{l}\text { Yeast extract and metal ions } \\
(\%, w / v)\end{array}$} & \multicolumn{16}{|c|}{ Incubation Time (h) } \\
\hline \multirow[t]{2}{*}{ Yeast extract } & \multirow[b]{2}{*}{ A } & \multicolumn{2}{|l|}{12} & \multicolumn{2}{|l|}{24} & \multicolumn{2}{|l|}{36} & \multicolumn{2}{|l|}{48} & \multicolumn{2}{|l|}{60} & \multicolumn{2}{|l|}{72} & \multicolumn{2}{|l|}{84} & \multirow{2}{*}{$\begin{array}{l}96 \\
B\end{array}$} & \\
\hline & & B & $A$ & B & A & B & A & B & A & B & A & B & A & B & A & & \\
\hline Yeast extract & $(0.0)$ & 9 & 0.96 & 17 & 2.41 & 28 & 3.21 & 41 & 3.52 & 66 & 3.74 & 89 & 3.66 & 84 & 3.60 & 81 & 3.51 \\
\hline Yeast extract & $(0.1)$ & 14 & 1.08 & 31 & 2.40 & 52 & 3.40 & 76 & 3.75 & 93 & 3.84 & 110 & 3.72 & 108 & 3.65 & 105 & 3.61 \\
\hline Yeast extract & $(0.2)$ & 17 & 1.16 & 54 & 2.47 & 67 & 3.46 & 103 & 3.82 & 154 & 3.95 & 178 & 3.81 & 170 & 3.74 & 159 & 3.69 \\
\hline Yeast extract & $(0.3)$ & 20 & 1.18 & 65 & 2.49 & 92 & 3.67 & 152 & 4.21 & 203 & 4.38 & 219 & 4.20 & 213 & 4.14 & 208 & 4.07 \\
\hline Yeast extract & $(0.4)$ & 28 & 1.21 & 79 & 2.53 & 109 & 3.79 & 167 & 4.63 & 227 & 4.77 & 255 & 4.64 & 246 & 4.58 & 239 & 4.50 \\
\hline Yeast extract & $(0.5)$ & 29 & 1.23 & 84 & 2.62 & 115 & 3.84 & 182 & 4.71 & 239 & 4.96 & 278 & 4.87 & 269 & 4.80 & 251 & 4.71 \\
\hline Yeast extract & (0.6) & 26 & 1.30 & 67 & 2.97 & 105 & 4.11 & 178 & 4.91 & 231 & 5.17 & 269 & 5.04 & 257 & 4.97 & 248 & 4.91 \\
\hline Yeast extract & $(0.7)$ & 21 & 1.39 & 48 & 3.16 & 92 & 4.50 & 163 & 5.20 & 227 & 5.35 & 246 & 5.26 & 241 & 5.18 & 237 & 5.03 \\
\hline \multicolumn{18}{|l|}{ Metal ions } \\
\hline No metal & & 29 & 1.23 & 84 & 2.62 & 115 & 3.84 & 182 & 4.71 & 239 & 4.96 & 278 & 4.87 & 269 & 4.80 & 251 & 4.71 \\
\hline $\mathrm{ZnSO}_{4}$ & $(0.01)$ & 6 & 1.34 & 17 & 3.62 & 36 & 4.93 & 67 & 5.82 & 92 & 6.05 & 103 & 5.87 & 100 & 5.54 & 94 & 5.17 \\
\hline $\mathrm{CuSO}_{4}$ & $(0.01)$ & 5 & 0.51 & 12 & 1.32 & 41 & 2.15 & 98 & 2.62 & 159 & 2.94 & 186 & 2.77 & 182 & 2.61 & 174 & 2.54 \\
\hline $\mathrm{FeCl}_{2}$ & $(0.01)$ & 8 & 0.62 & 31 & 1.40 & 74 & 1.95 & 154 & 2.17 & 186 & 2.31 & 210 & 2.27 & 207 & 2.08 & 201 & 1.83 \\
\hline $\mathrm{MnSO}_{4}$ & $(0.01)$ & 4 & 0.82 & 15 & 1.43 & 34 & 3.05 & 78 & 3.67 & 133 & 4.15 & 147 & 3.94 & 145 & 3.80 & 141 & 3.64 \\
\hline $\mathrm{CaCl}_{2}$ & $(0.01)$ & 33 & 1.16 & 86 & 3.08 & 143 & 4.60 & 196 & 5.23 & 289 & 5.82 & 342 & 5.53 & 336 & 5.38 & 327 & 4.94 \\
\hline $\begin{array}{l}\mathrm{MgSO}_{4} \\
+\mathrm{CaCl}_{2}\end{array}$ & $(0.005+0.005)$ & 36 & 1.19 & 92 & 2.97 & 158 & 4.82 & 209 & 5.34 & 318 & 5.95 & 377 & 5.76 & 372 & 5.60 & 364 & 5.23 \\
\hline $\mathrm{MgSO}_{4}$ & $(0.005)$ & 36 & 1.23 & 77 & 2.86 & 159 & 3.90 & 216 & 5.69 & 297 & 5.91 & 354 & 5.57 & 349 & 5.21 & 342 & 5.19 \\
\hline $\mathrm{MgSO}_{4}$ & $(0.01)$ & 41 & 1.20 & 106 & 3.10 & 197 & 4.73 & 304 & 6.07 & 386 & 6.18 & 431 & 6.10 & 428 & 5.83 & 417 & 5.26 \\
\hline $\mathrm{MgSO}_{4}$ & $(0.02)$ & 38 & 1.80 & 81 & 4.13 & 175 & 5.20 & 286 & 6.22 & 364 & 6.38 & 378 & 6.15 & 376 & 6.03 & 371 & 5.86 \\
\hline $\mathrm{MgSO}_{4}$ & $(0.03)$ & 35 & 1.62 & 62 & 3.57 & 139 & 5.14 & 246 & 6.11 & 327 & 6.15 & 356 & 5.96 & 352 & 5.81 & 346 & 5.66 \\
\hline $\mathrm{MgSO}_{4}$ & $(0.04)$ & 34 & 1.45 & 66 & 3.40 & 122 & 4.93 & 212 & 5.88 & 305 & 5.07 & 321 & 5.82 & 314 & 5.73 & 306 & 5.43 \\
\hline $\mathrm{MgSO}_{4}$ & $(0.05)$ & 27 & 1.40 & 59 & 2.89 & 108 & 4.76 & 176 & 5.32 & 264 & 5.73 & 309 & 5.24 & 301 & 5.10 & 296 & 5.08 \\
\hline
\end{tabular}

Effect of physical parameters on bacterial growth and protease production in optimized medium containing ( $\mathrm{gl}^{-1}$ distilled water): glucose, 10.0; gelatin, 20.0; yeast extract, 5.0 and $\mathrm{MgSO}_{4} .7 \mathrm{H}_{2} \mathrm{O}, 0.1$

\begin{tabular}{|c|c|c|c|c|c|c|c|c|c|c|c|c|c|c|c|c|c|}
\hline \multicolumn{18}{|c|}{ Incubation Time (h) } \\
\hline \multirow[t]{2}{*}{$\mathrm{pH}$} & \multirow[b]{2}{*}{ A } & \multicolumn{2}{|l|}{12} & \multicolumn{2}{|l|}{24} & \multicolumn{2}{|l|}{36} & \multicolumn{2}{|l|}{48} & \multicolumn{2}{|l|}{60} & \multicolumn{2}{|l|}{72} & \multicolumn{2}{|l|}{84} & \multirow{2}{*}{$\begin{array}{l}96 \\
\text { B }\end{array}$} & \\
\hline & & B & A & B & A & B & A & B & A & $B$ & A & B & A & B & A & & \\
\hline 7.0 & & 00 & 0.63 & 00 & 1.73 & 00 & 2.95 & 00 & 4.38 & 00 & 4.92 & 00 & 4.78 & 00 & 4.64 & 00 & 4.51 \\
\hline 7.5 & & 00 & 0.69 & 00 & 1.83 & 7 & 3.06 & 19 & 4.57 & 32 & 5.10 & 38 & 4.85 & 35 & 4.69 & 31 & 4.32 \\
\hline 8.0 & & 12 & 0.93 & 21 & 2.40 & 34 & 3.32 & 48 & 4.87 & 64 & 5.30 & 87 & 5.14 & 81 & 5.02 & 78 & 4.85 \\
\hline 8.5 & & 30 & 1.18 & 76 & 3.04 & 165 & 4.52 & 213 & 5.77 & 294 & 6.08 & 311 & 5.84 & 308 & 5.61 & 304 & 5.22 \\
\hline 9.0 & & 41 & 1.20 & 106 & 3.10 & 197 & 4.73 & 304 & 6.07 & 386 & 6.18 & 431 & 6.10 & 428 & 5.83 & 417 & 5.26 \\
\hline 9.5 & & 5 & 1.08 & 17 & 3.06 & 48 & 4.26 & 92 & 5.17 & 135 & 5.50 & 146 & 5.34 & 143 & 5.21 & 138 & 5.02 \\
\hline 10.0 & & 00 & 0.25 & 00 & 0.34 & 00 & 0.21 & 00 & 0.19 & 00 & 0.16 & 00 & 0.13 & 00 & 0.12 & 00 & 0.09 \\
\hline \multicolumn{18}{|c|}{ Agitation speed (rpm) } \\
\hline 50 & & 14 & 0.62 & 26 & 1.44 & 41 & 2.58 & 58 & 3.06 & 81 & 3.30 & 97 & 3.16 & 95 & 3.08 & 93 & 3.01 \\
\hline 100 & & 27 & 0.93 & 93 & 2.17 & 139 & 3.86 & 187 & 4.23 & 249 & 4.95 & 283 & 4.70 & 279 & 4.40 & 273 & 4.19 \\
\hline 150 & & 41 & 1.20 & 106 & 3.10 & 197 & 4.73 & 304 & 6.07 & 386 & 6.18 & 431 & 6.10 & 428 & 5.83 & 417 & 5.26 \\
\hline 200 & & 53 & 1.46 & 127 & 3.81 & 261 & 5.48 & 375 & 6.32 & 514 & 6.21 & 509 & 6.03 & 501 & 5.64 & 492 & 5.17 \\
\hline 250 & & 46 & 1.30 & 113 & 4.05 & 254 & 5.72 & 368 & 6.29 & 491 & 6.14 & 483 & 5.80 & 476 & 5.64 & 468 & 5.37 \\
\hline \multicolumn{18}{|c|}{ Temperature $\left({ }^{\circ} \mathrm{C}\right)$} \\
\hline 10 & & 4 & 0.42 & 10 & 0.79 & 18 & 1.13 & 27 & 1.84 & 32 & 2.26 & 46 & 2.81 & 53 & 2.51 & 51 & 2.42 \\
\hline 15 & & 13 & 0.61 & 32 & 1.06 & 59 & 1.92 & 104 & 2.68 & 167 & 3.96 & 219 & 3.74 & 217 & 3.58 & 216 & 3.42 \\
\hline 20 & & 24 & 0.92 & 45 & 1.75 & 112 & 3.87 & 287 & 5.11 & 423 & 4.83 & 421 & 4.70 & 418 & 4.47 & 413 & 4.26 \\
\hline 25 & & 53 & 1.46 & 127 & 3.81 & 261 & 5.48 & 375 & 6.32 & 514 & 6.21 & 509 & 6.03 & 501 & 5.64 & 492 & 5.17 \\
\hline 30 & & 31 & 1.14 & 84 & 2.59 & 196 & 4.05 & 308 & 5.40 & 435 & 5.27 & 431 & 5.13 & 427 & 4.86 & 421 & 4.33 \\
\hline 35 & & 18 & 0.85 & 31 & 1.92 & 58 & 2.73 & 87 & 3.42 & 132 & 3.25 & 132 & 3.14 & 129 & 3.01 & 126 & 2.90 \\
\hline 40 & & 2 & 0.80 & 3 & 1.43 & 7 & 1.84 & 10 & 2.17 & 12 & 1.94 & 11 & 1.72 & 8 & 1.54 & 6 & 1.24 \\
\hline
\end{tabular}


the supply of dissolved oxygen and uptake of nutrients to the bacterial cells. The decreased enzyme production at $>200 \mathrm{rpm}$ was perhaps due to denaturation of proteases caused by the mechanical damage.

Shaking of aerobic bacterial culture is one of the most decisive factors for growth and protease production, as agitation maintains proper oxygen supply and mixing of growing cells. Oxygen transfer into bacterial cells in aerobic fermentation process strongly affects growth and enzyme production by affecting the metabolic pathways and fluxes [23]. Several other researchers also reported maximum protease production at an agitation speed of $200 \mathrm{rpm}$ [22]. Gupta and Khare [3] reported maximum protease production by $P$. aeruginosa PseA at $250 \mathrm{rpm}$.

\section{Temperature}

In any bioprocess, specific temperature requirement and its regulation is one of the most critical parameters. Strain SKG-1 was able to grow and produce protease in complete temperature range $\left(10^{\circ}-40^{\circ} \mathrm{C}\right)$ of study with maximum production at optimum $25^{\circ} \mathrm{C}$. Temperature higher or lower than optimum, reduced the bacterial growth, thereby steady decrease in enzyme production (Table 5). The order of enzyme production at other temperatures was $\left(\mathrm{Uml}^{-1}\right): 10^{\circ} \mathrm{C}(53)<15^{\circ} \mathrm{C}(219)<20^{\circ} \mathrm{C}(423)<25^{\circ} \mathrm{C}$ $(514)>30^{\circ} \mathrm{C}(435)>35^{\circ} \mathrm{C}(132)>40^{\circ} \mathrm{C}(12)$.

The ability of strain SKG-1 to grow at wide temperature range of $10^{\circ}-40^{\circ} \mathrm{C}$ with optimum at $25^{\circ} \mathrm{C}$ revealed its psychrotrophic nature. Only few psychrotrophic bacterial isolates have been reported for thermostable alkaline protease production. Jackman et al. [24] reported heat stable protease production at $25^{\circ} \mathrm{C}$ from psychrotrophic pseudomonads. A psychrotrophic Exiguobacterium sp. SKPB5 produced alkaline protease at $30^{\circ} \mathrm{C}$ with maximum protease activity at $50^{\circ} \mathrm{C}$ [25].

\section{Incubation time}

The bacterial growth and protease production were in harmony up to $54 \mathrm{~h}$ under optimized nutritional and cultural conditions. Bacterial growth was in the exponential phase up to $54 \mathrm{~h}$; thereafter entered the stationary phase. Whereas, enzyme production reached maximum $\left(514 \mathrm{Uml}^{-1}\right)$ during early stationary phase at $60 \mathrm{~h}$; thereafter remained nearly constant up to $72 \mathrm{~h}$ fermentation (Figure 2). Our findings are in accordance with the results of several other researchers $[3,10]$. Zeng et al. [26] reported maximum protease production of only $45 \mathrm{Uml}^{-1}$ at $10^{\circ} \mathrm{C}$ from Pseudomonas sp. strain DY-A during the late stationary phase of growth.

\section{Statistical optimization of factors affecting protease production by RSM}

The response surface methodology (RSM) is widely applied by many researchers to optimize alkaline protease production from several bacteria and fungi. However, there is no report on statistical optimization of

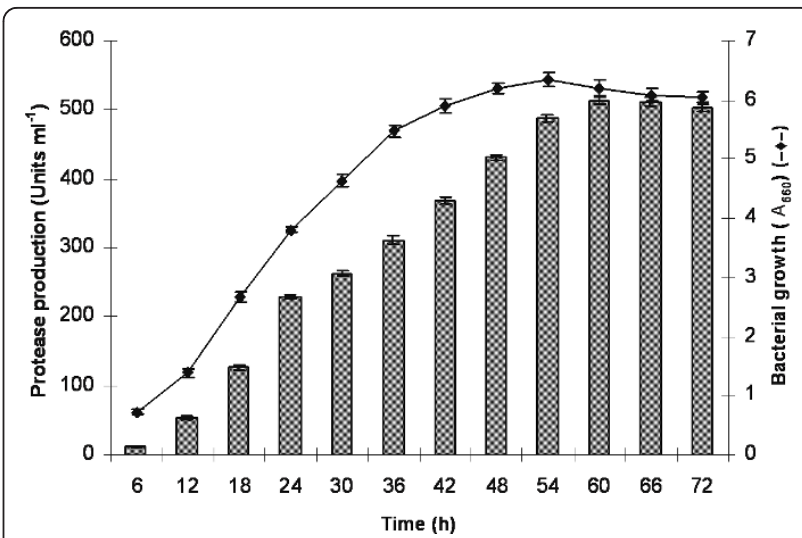

Figure 2 Protease production and growth response of $P$. putida SKG-1 in finally optimized medium containing $\left(\mathrm{gl}^{-1}\right.$ distilled water): glucose, 10.0; gelatin, 20.0; yeast extract, 5.0 and $\mathrm{MgSO}_{4}, 0.1$ at initial $\mathrm{pH} 9.0,25^{\circ} \mathrm{C}$ and $200 \mathrm{rpm}$ during 72 $h$ growth.

alkaline protease by Pseudomonas putida. Interactive effects of the most important conventionally optimized factors, viz., glucose, yeast extract, $\mathrm{MgSO}_{4}$ and $\mathrm{pH}$ were examined by RSM using Box-Behnken design. Analysis of variance (ANOVA) yielded the following regression equation in terms of the protease levels produced $(\mathrm{Y})$ as a function of glucose (A), yeast extract (B), $\mathrm{MgSO}_{4}(\mathrm{C})$ and $\mathrm{pH}(\mathrm{D})$ :

$$
\begin{aligned}
& Y=514+17.50 \times A+15.25 \times B+9.75 \times C-75.83 \times C+6.50 \times \\
& A^{2}-63.37 \times B^{2}-46.37 \times C^{2}-9.25 \times D^{2}-1.25 \times A B-0.25 \times \\
& A C-8.0 \times A D-9 \times B C+16 \times B D+2.0 \times C D
\end{aligned}
$$

Table 2 shows predicted responses of Box-Behnken design on the basis of above polynomial equation. This regression equation was assessed statistically for analysis of variance (ANOVA), and the results are predicted in Table 3. ANOVA of regression model demonstrated the determination coefficient $\left(R^{2}\right) 0.9988$, which means $99.88 \%$ variability in the response could be explained by this model. The $\mathrm{R}^{2}$ value is always between 0 and 1.0. The model is stronger and predicts better response when $\mathrm{R}^{2}$ value is closer to 1.0 [5]. The value of the adjusted determination coefficient (adjusted $R^{2}$ ) is 0.9976 . This higher value of adjusted $R^{2}$ indicates greater significance of the model. A very low value of coefficient of variation (C.V., $0.70 \%$ ) indicates better precision and reliability of the experiments executed. The adequate precision value of 121.595 measures signal to noise ratio, and a ratio $>4.0$ is desirable. In this case, higher ratio indicates an adequate signal, and also proves that model can be used to navigate the design space.

The F-value of 820.46 in Table 3 implies that the model is significant. There is only $0.01 \%$ chance that a 
"model F-value" so large could occur due to noise. ANOVA analysis also indicated that the model term linear glucose $(\mathrm{P}<0.0001)$, yeast extract $(\mathrm{P}<0.0001)$, $\mathrm{MgSO}_{4}(\mathrm{P}<0.0001), \mathrm{pH}(\mathrm{P}<0.0001)$, quadratic glucose $\mathrm{A}^{2}(\mathrm{P}<0.0002)$, yeast extract $\mathrm{B}^{2}(\mathrm{P}<0.0001), \mathrm{MgSO}_{4}$ $\mathrm{C}^{2}(\mathrm{P}<0.0001), \mathrm{pH} \mathrm{D}^{2}(\mathrm{P}<0.0001)$ and four interaction terms were significant. Smaller the $\mathrm{P}$-value, more significant is the corresponding coefficient. The $\mathrm{P}<0.0500$ indicates that model terms are significant.

The $3 \mathrm{D}$ response surface plots and two dimensional contour plots were used to understand the interaction effects of medium components and optimum concentration of each component required for maximum protease production. Response surface curves for variation in alkaline protease yield were constructed, and are depicted in Figure 3. In each set, two variables varied within their experimental range, while the other two variables remained constant at zero level.

Figure 3a depicts the production of alkaline protease with respect to glucose versus yeast extract. From the interaction response of glucose with yeast extract, protease yields increased with increasing glucose and yeast extract concentration up to $1.25 \%$ and $0.5 \%$, respectively. The enzyme activity decreased at $>0.5 \%$ yeast extract concentration. However, the response curve did not show curvature, rather it was flattened. This suggested a demand for higher concentration of glucose. Figure $3 \mathrm{~b}$ represents the interaction effect of glucose and $\mathrm{MgSO}_{4}$ on production of alkaline protease. With an increase in glucose $(0.75-1.25 \%$, $\mathrm{w} / \mathrm{v})$ and $\mathrm{MgSO}_{4}(0.0075-0.01 \%, \mathrm{w} / \mathrm{v})$ concentration, the protease yield increased. Thereafter, an increase in $\mathrm{MgSO}_{4}$ concentration up to $0.0125 \%(\mathrm{w} / \mathrm{v})$ resulted in decreased protease production. The optimal values for glucose and $\mathrm{MgSO}_{4}(\mathrm{w} / \mathrm{v})$ were 1.25 and $0.01 \%$, respectively.

Figure $3 \mathrm{c}$ reveals that maximum protease was produced at higher level of glucose $(1.25 \%)$ and slightly lower alkaline $\mathrm{pH}(8.8)$ in the design range. This accorded a run number of 10 , which is considered as the optimal condition of test variables. Table 2 shows that maximum protease of $617 \mathrm{Uml}^{-1}$ were produced at $\mathrm{pH} 8.8$ ( -1 in coded unit) and glucose at $1.25 \%(+1$ in coded unit). Figure $3 \mathrm{~d}$ depicts the interaction of two variables, viz., $\mathrm{MgSO}_{4}$ and yeast extract on protease production. The protease production increased with increasing concentration of $\mathrm{MgSO}_{4}(0.0075-0.01 \%$, w/v) and yeast extract $(0.3-0.5 \%, \mathrm{w} / \mathrm{v})$. Further increase in their concentrations resulted in decreased alkaline protease production.

Figure 3e illustrates the interaction effect of $\mathrm{pH}$ (8.8$9.2)$ and yeast extract $(0.3-0.7 \%)$ on alkaline protease production. Maximum enzyme units were produced with $0.5 \%$ yeast extract and $\mathrm{pH}$ 8.8. Further increase in $\mathrm{pH}$ and any deviation in yeast extract concentration from optimal, decreased the enzyme production. The effect of $\mathrm{pH}$ and $\mathrm{MgSO}_{4}$ is shown in Figure 3f. The response curve analysis indicated that protease production decreased with increase in $\mathrm{pH}$ from 8.8 to 9.2, and increased with enhanced concentration of $\mathrm{MgSO}_{4}$ up to $0.01 \%(\mathrm{w} / \mathrm{v})$. Further increase in $\mathrm{MgSO}_{4}$ concentration above $0.01 \%$ caused decreased enzyme yield.

The above optimized results (Table 2 standard order 10) concerning four variables were finally verified by again performing the batch shake flask experiment. The maximum experimental alkaline protease production of 617 $\mathrm{Uml}^{-1}$ was very close to $612 \mathrm{Uml}^{-1}$ predicted by Box-Behnken design with $1.25 \%$ glucose, $0.5 \%$ yeast extract, $0.01 \%$ $\mathrm{MgSO}_{4}$ and $\mathrm{pH}$ 8.8. Thus, under optimized conditions, the protease yield increased from 514 units in conventional optimization trial to $617 \mathrm{Uml}^{-1}$ using RSM at $60 \mathrm{~h}$ incubation. This proved that response surface methodology is a slightly better optimization approach as compared to conventional "one-variable-at-a-time" method in terms of improved protease yield in less time, resource and expenditure. Our findings are in agreement with the results of other researchers who have also reported RSM a better approach for enhanced protease production $[4,5,16]$. Reddy et al. [27] reported a 2.3 folds increase in alkaline protease production using Plackett-Burman and Response surface methodology by Bacillus sp. RKY3. Anbu et al. [28] obtained a good correlation coefficient of 0.9996 using Box-Behnken design and alkaline protease production of $112.90 \mathrm{Uml}^{-1}$ by Shewanella oneidensis MR1 strain through response surface optimization.

\section{Bench-scale bioreactor optimization Effect of aeration}

In this set of experiment, the bacterial growth and protease production were studied at a fixed agitation speed of $200 \mathrm{rpm}$ and variable aeration rates of $0-1.5 \mathrm{vvm}$ (Figure $4)$. The enzyme production was drastically low at aeration

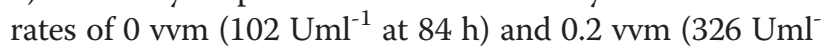
${ }^{1}$ at $72 \mathrm{~h}$ ). However, at 0.4 and $0.6 \mathrm{vvm}$, the protease production was $630 \mathrm{U}$ and $798 \mathrm{Uml}^{-1}$, respectively at $60 \mathrm{~h}$ incubation. Further increase in aeration rate to $0.8 \mathrm{vvm}$ produced maximum protease of $846 \mathrm{Uml}^{-1}$ at just $48 \mathrm{~h}$ fermentation. Still higher aeration rates of 1.0 and $1.5 \mathrm{vvm}$ were detrimental for protease production, and resulted in reduced $741 \mathrm{Uml}^{-1}$ in $48 \mathrm{~h}$ and $436 \mathrm{Uml}^{-1}$ in $60 \mathrm{~h}$, respectively (Figure 4). Bacterial growth pattern (Figure 5) was similar to protease production (Figure 4), which was very slow at lower aeration rates, and increased with increasing rate of aeration approaching maximum at $0.8 \mathrm{vvm}$. The DOT was initially $100 \%$ at $0 \mathrm{~h}$, which reduced rapidly with increasing bacterial growth. The DOT was inversely related with the bacterial growth, i.e., at maximum exponential bacterial growth, the DOT was minimum and started increasing after the onset of stationary growth phase (Figure 5). 


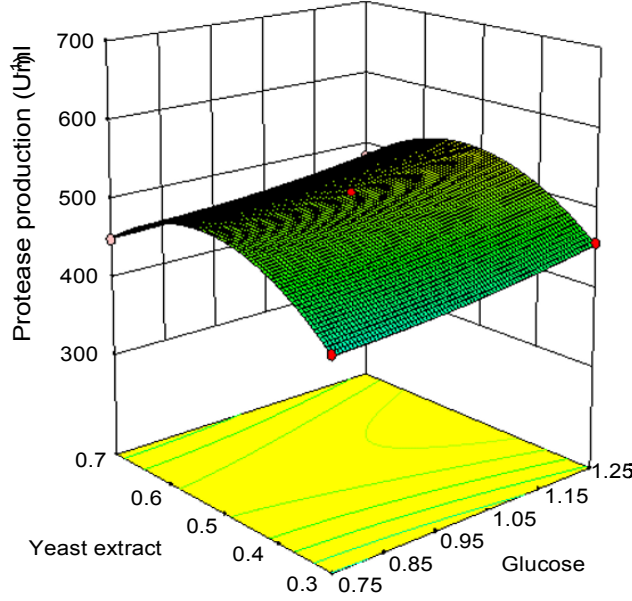

Fig. 3a

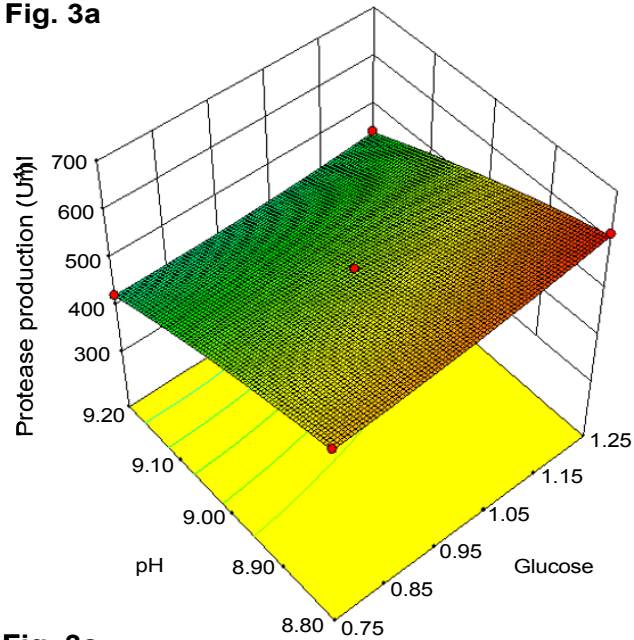

Fig. 3c

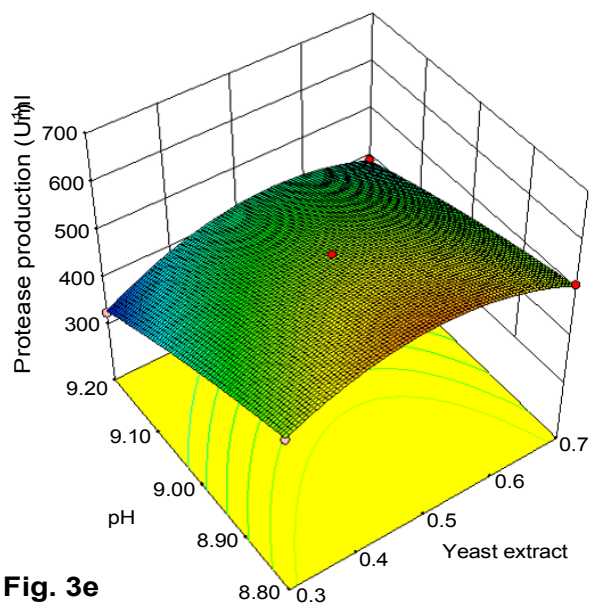

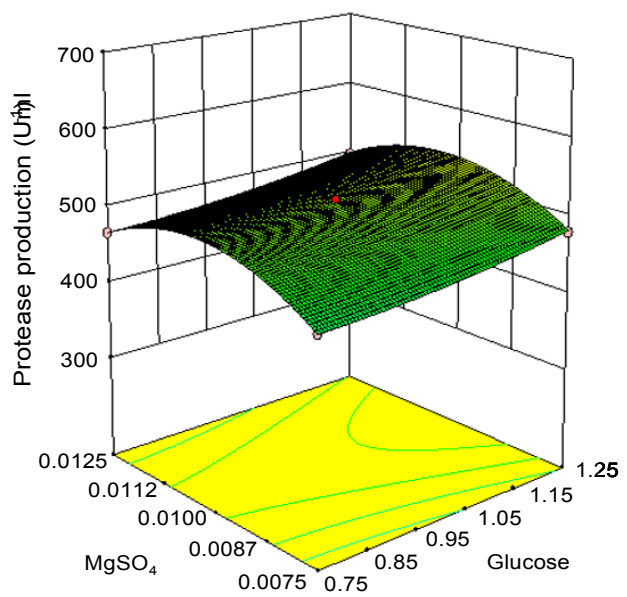

Fig. 3b

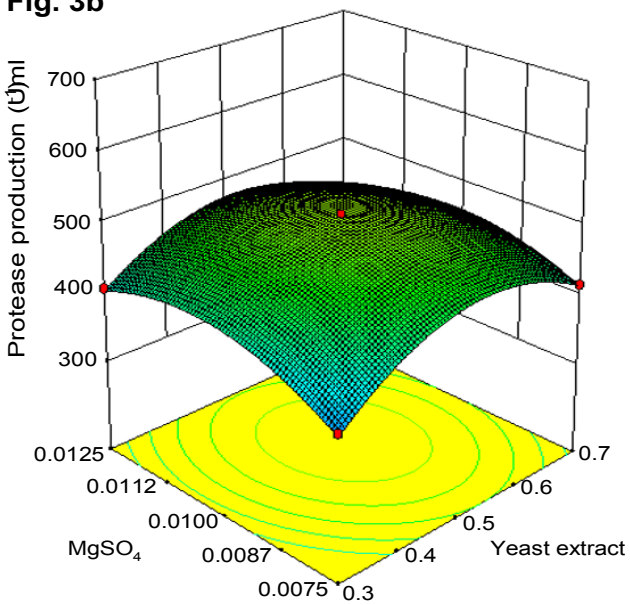

Fig. 3d

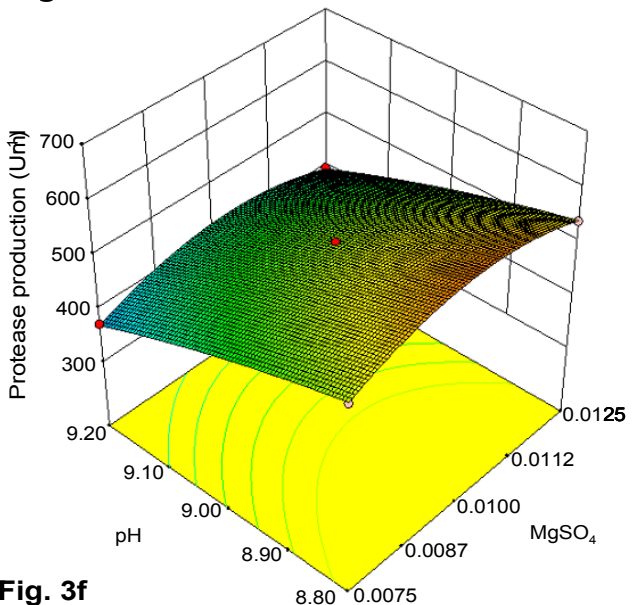

Figure 3 Response-surface curve of alkaline protease production by Pseudomonas putida SKG-1 showing mutual interactions between (a) glucose and yeast extract, (b) glucose and $\mathrm{MgSO}_{4}$, (c) glucose and $\mathrm{pH}$, (d) $\mathrm{MgSO}_{4}$ and yeast extract, (e) pH and yeast extract, (f) $\mathbf{p H}$ and $\mathbf{M g S O}_{4}$. Other variables, except for two in each figure, were maintained at zero level in coded units.

Under RSM optimized conditions, protease production was maximum at $60 \mathrm{~h}$ incubation, while it was highest in bioreactor trial at $48 \mathrm{~h}$, thereby led to significant time saving of $12 \mathrm{~h}$. Optimization of aeration rate at fixed agitation speed of $200 \mathrm{rpm}$ indicated that oxygen supply to bacterial cell mass is a critical parameter for enzyme 


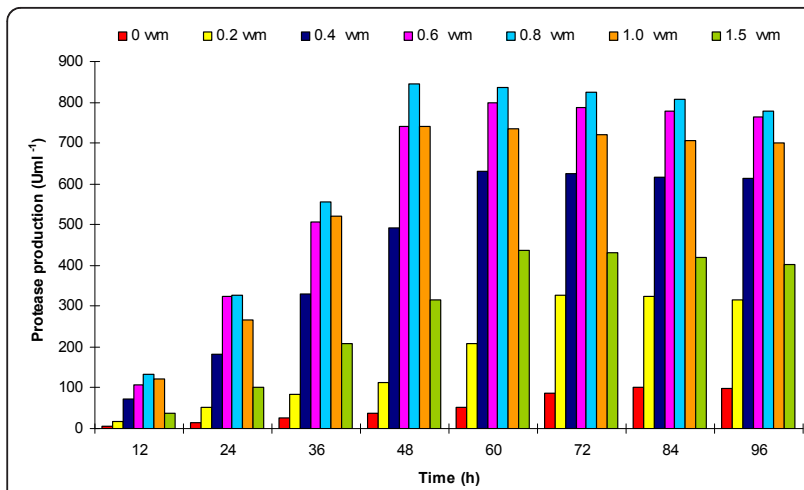

Figure 4 Effect of different aeration rates (0-1.5 vvm) at constant agitation speed $(200 \mathrm{rpm})$ on protease production.

production under aerobic fermentation process. This could be achieved by optimizing the agitation speed and maintaining proper aeration; however, an appropriate balance of agitation and aeration is imperative to avoid any mechanical damage to bacterial cells which can reduce the enzyme yield. From the results of aeration optimization, it can be inferred that a direct correlation existed between bacterial growth and protease production. The reduction in DOT followed a similar pattern as experienced in previous experiment. It reduced rapidly during exponential growth phase, and rose again on commencement of stationary phase onwards (Figure 5). Rao et al. [29] reported highest protease production of 238.77 $\mathrm{Uml}^{-1}$ by a Beauveria bassiana isolate on $6^{\text {th }}$ day of fermentation in a 5 litre stirred tank bioreactor at $150 \mathrm{rpm}$ and $0.6 \mathrm{vvm}$ aeration. Maximum protease of $340 \mathrm{Uml}^{-1}$ by Bacillus licheniformis NCIM-2042 was reported at aeration and agitation rates of $3 \mathrm{vvm}$ and $200 \mathrm{rpm}$, respectively [7].

\section{Effect of agitation at optimized aeration}

After optimization of suitable aeration rate $(0.8 \mathrm{vvm})$, we attempted to optimize agitation speed (100-250 rpm) for studying its effect on protease yield and the results are

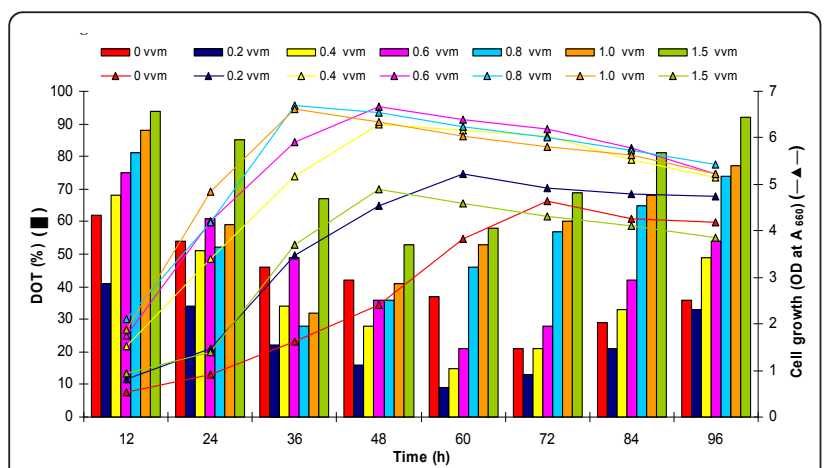

Figure 5 Effect of different aeration rates (0-1.5 vvm) at constant agitation speed $(200 \mathrm{rpm})$ on bacterial growth and change in DOT profile. depicted in Figure 6. The enzyme production enhanced with increase in agitation rate, which was maximum at $150 \mathrm{rpm}$ within $48 \mathrm{~h}$ of incubation. The order of protease units produced at 250, 200 and $150 \mathrm{rpm}$ were $\left(\mathrm{Uml}^{-1}\right): 817<846<882$ during 48 h fermentation. However, further decrease in agitation speed to $100 \mathrm{rpm}$ reduced the enzyme yield only to $761 \mathrm{Uml}^{-1}$ at extended $60 \mathrm{~h}$ incubation (Figure 6). Throughout the study, the DOT started declining concomitantly with increase in bacterial growth, and reached minimum when bacterial growth was maximum. After commencement of stationary phase, the DOT again increased slowly (Figure 7). At optimized fixed aeration rate of $0.8 \mathrm{vvm}$ and 150 rpm agitation, the DOT initially declined to $92 \%$ at $6 \mathrm{~h}$ incubation. It further declined sharply with increasing bacterial biomass, and approached minimum (18\%) at $42 \mathrm{~h}$, followed by slow increase to $49 \%$ at $72 \mathrm{~h}$ incubation (Figure 8). Thus, the protease production enhanced by $\sim 43 \%\left(882 \mathrm{Uml}^{-1}\right)$ at bench-scale bioreactor level during $48 \mathrm{~h}$ incubation compared to the conventional and RSM optimization at flask level $\left(617 \mathrm{Uml}^{-1}\right)$ during $60 \mathrm{~h}$ batch fermentation.

It is evident from the findings that an optimum agitation of fermenting broth is necessary for proper oxygen supply to bacterial cells. However, above the optimum speed it may damage the cells or change the cell morphology, which leads to reduced protease yield. Maximum protease production at $300 \mathrm{rpm}$ has also been reported by Potumarthi et al. [7] in a stirred tank bioreactor. Any deviation in agitation speed to 200 or $400 \mathrm{rpm}$ reduced the protease yield. They concluded that mixing is important for maximal protease production by optimizing both agitation and aeration for better oxygen mass transfer rate. This results in better product formation through avoiding/minimizing any mechanical damage to the bacterial cells. Many other researchers also reported the optimum agitation speed range of 150-300 rpm for protease production from

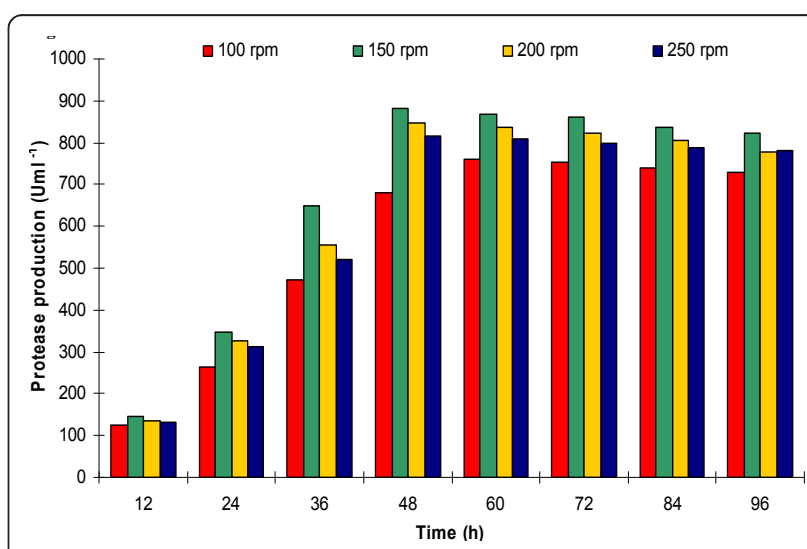

Figure 6 Effect of different agitation speeds (100-250 rpm) at constant aeration rate $(0.8 \mathrm{vvm})$ on protease production. 


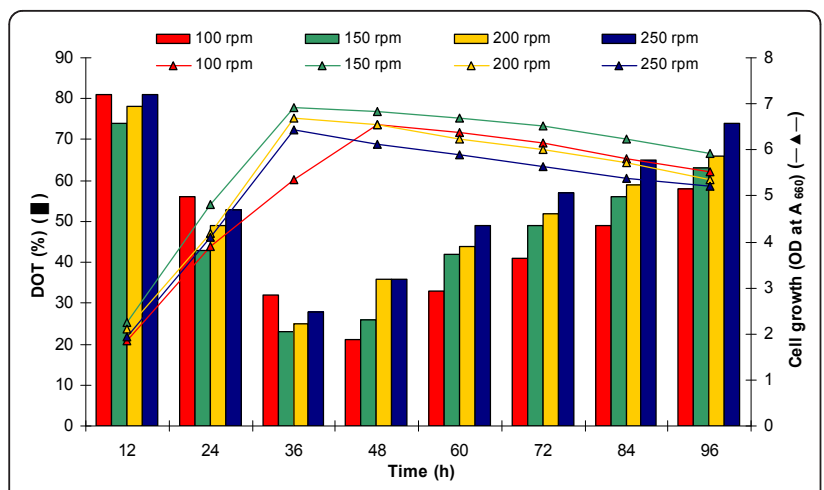

Figure 7 Effect of different agitation speeds (100-250 rpm) at constant aeration rate $(0.8 \mathrm{vvm})$ on bacterial growth and change in DOT profile.

different isolates [30-32]. It may, therefore, be inferred that a proper ratio of agitation and aeration is mandatory for appropriate oxygen transfer to bacterial cell mass, and also to minimize the shearing effect for maximum growth and protease production.

\section{Conclusions}

The optimization of alkaline protease production from Pseudomonas putida is being reported by conventional as well as statistical response surface methodologies. A 7.9 folds (from 65 to $514 \mathrm{Uml}^{-1}$ ) increase in protease production was evident with optimized nutritional (glucose 1\%, gelatin $2 \%$, yeast extract $0.5 \%, \mathrm{Mg}^{2+} 0.01 \%$ ) and cultural $\left(\mathrm{pH} 9.0,25^{\circ} \mathrm{C}, 200 \mathrm{rpm}\right)$ conditions during early stationary phase at $60 \mathrm{~h}$ fermentation employing conventional method of optimization. Whereas, the response surface methodology enhanced the protease production to 9.5 folds $\left(617 \mathrm{Uml}^{-1}\right)$ by further optimizing the glucose concentration to $1.25 \%(\mathrm{w} / \mathrm{v})$ and $\mathrm{pH}$ to 8.8 . The optimization of process parameters by RSM proved it a time/ resource saving and efficient method. Although, it

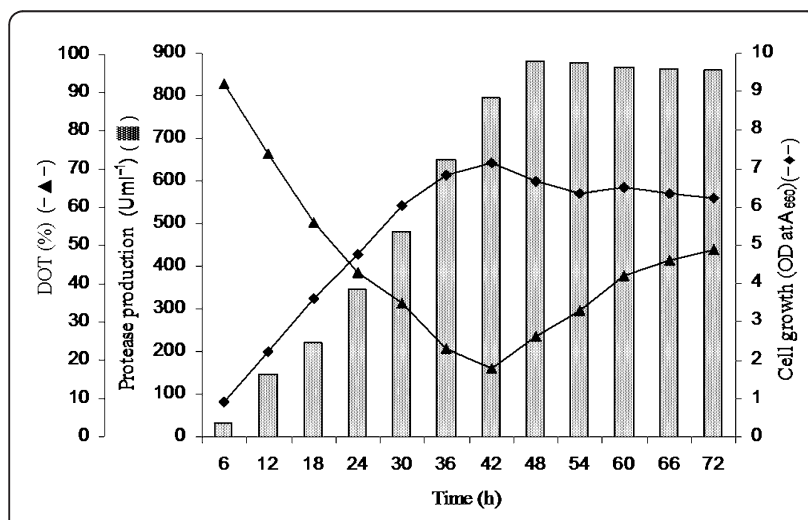

Figure 8 Pattern of bacterial growth, enzyme production and DOT change in GGY broth at $150 \mathrm{rpm}$ and $0.8 \mathrm{vvm}$ aeration at $\mathrm{pH} 9.0$ and $25^{\circ} \mathrm{C}$. provided better insight of interactions among the parameters that affect enzyme production, development of a better statistical tool is a constant endeavor. Further optimization of agitation $(150 \mathrm{rpm})$ and aeration $(0.8 \mathrm{vvm})$ rates at bench-scale bioreactor level enhanced the enzyme production by $\sim 43 \%\left(882 \mathrm{Uml}^{-1}\right)$ at $48 \mathrm{~h}$ fermentation. It not only enhanced the protease yield, but also led to a significant time saving of $12 \mathrm{~h}$. Furthermore, this is the first report on such a high yield of solvent and psychro-thermo-alkali-stable protease from a solvent tolerant psychrotrophic bacterial strain.

\section{Acknowledgements}

The senior author Santosh K Singh is thankful to University Grants Commission, Government of India, New Delhi, for providing research fellowship under the major research project [Project no. 37-521/2009 (SR)]. The assistance provided by Government of Uttar Pradesh and Department of Science and Technology, Government of India, respectively under the schemes of Center of Excellence and DST-FIST, is duly acknowledged. The help in RSM studies rendered by Dr. Sunil Kumar Tyagi, Department of Statistics, Narendra Dev University of Agriculture and Technology, Faizabad, India, is gratefully acknowledged.

\section{Author details}

${ }^{1}$ Center of Excellence, Department of Microbiology, Dr. Ram Manohar Lohia Avadh University, Faizabad-224001, UP, India. ${ }^{2}$ Department of Chemistry, Indian Institute of Technology, Hauz-Khas, New Delhi-1 10016, India.

\section{Authors' contributions}

1. SKS carried out the research work and drafted the manuscript. 2. SKS was involved in data processing and manuscript preparation 3. VRT was involved in revising the manuscript critically for important intellectual contents.

4. SKK was involved in data verification and designed the optimization experiment.

5. SKG has designed the experiment(s), contributed substantially to analysis and interpretation of data and has given final approval of the version to be published.

All authors read and approved the final manuscript.

\section{Competing interests}

The authors declare that they have no competing interests.

Received: 4 October 2011 Accepted: 28 December 2011 Published: 28 December 2011

\section{References}

1. Adinarayana K, Ellaiah P, Siva Prasad D: Purification and partial characterization of thermostable serine alkaline protease from a newly isolated Bacillus subtilis PE-11. AAPS PharmSciTech 2003, 4:56.

2. Joo HS, Kumar CG, Park GC, Paik SR, Chang CS: Oxidant and SDS-stable alkaline protease from Bacillus clausii I-52: production and some properties. J Appl Microbiol 2003, 95:267-272.

3. Gupta A, Khare SK: Enhanced production and characterization of a solvent stable protease from solvent tolerant Pseudomonas aeruginosa PseA. Enz Microbial Technol 2007, 42:11-16.

4. Vishwanatha KS, Rao AGA, Singh SA: Acid protease production by solidstate fermentation using Aspergillus oryzae MTCC 5341: optimization of process parameters. J Ind Microbiol Biotechnol 2010, 37:129-138,

5. Doddapaneni KK, Tatineni R, Potumarthi R, Mangamoori LN: Optimization of media constituents through response surface methodology for improved production of alkaline proteases by Serratia rubidaea. J Chem Technol Biotechnol 2007, 82:721-729.

6. Calik P, Calik G, Ozdamar TH: Oxygen transfer effects in serine alkaline protease fermentation by Bacillus licheniformis: Use of citric acid as the carbon source. Enz Microbial Technol 1998, 23:451-461. 
7. Potumarthi R, Ch S, Jetty A: Alkaline protease production by submerged fermentation in stirred tank reactor using Bacillus licheniformis NCIM2042: Effect of aeration and agitation regimes. Biochem Eng J 2007, 34:185-192.

8. Hameed A, Keshavarz T, Evans CS: Effect of dissolved oxygen tension and $\mathrm{pH}$ on the production of extracellular protease from a new isolate of Bacillus subtilis $\mathrm{K} 2$, for use in leather processing. J Chem Technol Biotechnol 1999, 74:5-8

9. Singh SK, Singh SK, Tripathi VR, Khare SK, Garg SK: A novel psychrotrophic, solvent tolerant Pseudomonas putida SKG-1 and solvent stability of its psychro-thermoalkalistable protease. Process Biochem 2011, 46:1430-1435.

10. Singh SK, Tripathi VR, Jain RK, Vikram S, Garg SK: An antibiotic, heavy metal resistant and halotolerant Bacillus cereus SIU1 and its thermoalkaline protease. Microb Cell Fact 2010, 9:59.

11. Shimogaki H, Takeuchi K, Nishino T, Odera M, Kudo T, Ohba K, Iwama M, Irie M: Purification and properties of a novel surface active agent and alkaline resistant protease from Bacillus spp. Y. Agric Biol Chem 1991, 55:2251-2258.

12. Shafee N, Aris SN, Rahman RNZRA, Basri M, Salleh AB: Optimization of environmental and nutritional conditions for the production of alkaline protease by newly isolated bacterium Bacillus cereus strain 146. J App/ Sci Res 2005, 1:1-8.

13. Rahman RNZRA, Basri M, Salleh AB: Thermostable alkaline protease from Bacillus stearothermophilus F1; Nutritional factors affecting protease production. Ann Microbiol 2003, 53:199-210.

14. Nadeem M, Qazi Jl, Baig S, Syed Q: Effect of medium composition on commercially important alkaline protease production by Bacillus licheniformis N-2. Food Technol Biotechnol 2008, 46:388-394.

15. Kumar CG, Takagi H: Microbial alkaline proteases: from a bioindustrial viewpoint. Biotechnol Adv 1999, 17:561-594.

16. Puri S, Beg QK, Gupta R: Optimization of alkaline protease production from Bacillus sp. by response surface methodology. Curr Microbiol 2002, 44:286-290.

17. Rahman RNZRA, Geok LP, Basri M, Salleh AB: An organic solvent-tolerant protease from Pseudomonas aeruginosa strain K: Nutritional factors affecting protease production. Enz Microbial Technol 2005, 36:749-757.

18. Thumar J, Singh SP: Secretion of an alkaline protease from a salt-tolerant and alkaliphilic, Streptomyces clavuligerus strain MIT-1. Braz J Microbio 2007, 38:766-772.

19. Mabrouk SS, Hashem AM, El-Shayeb NMA, Ismail MS, Abdel-Fattah AF: Optimization of alkaline protease productivity by Bacillus licheniformis ATCC 21415. Biores Technol 1999, 69:155-159.

20. Joshi GK, Kumar S, Sharma V: Production of moderately halotolerant, SDS stable alkaline protease from Bacillus cereus MTCC 6840 isolated from lake Nainital, Uttaranchal state, India. Braz J Microbiol 2007, 38:773-779.

21. Chu $\mathrm{W}-\mathrm{H}$ : Optimization of extracellular alkaline protease production from species of Bacillus. J Ind Microbiol Biotechnol 2007, 34:241-245.

22. Abusham RA, Rahman RNZRA, Salleh AB, Basri M: Optimization of physical factors affecting the production of thermo-stable organic solventtolerant protease from a newly isolated halo tolerant Bacillus subtilis strain Rand. Microb Cell Fact 2009, 8:20.

23. Calik P, Calik G, Ozdamar TH: Oxygen-transfer strategy and its regulation effects in serine alkaline protease production by Bacillus licheniformis. Biotechnol Bioeng 2000, 69:301-311.

24. Jackman DM, Bartlett FM, Patel TR: Heat-stable proteases from psychrotrophic pseudomonads: comparison of immunological properties. Appl Environ Microbiol 1983, 46:6-12.

25. Kasana RC, Yadav SK: Isolation of a psychrotrophic Exiguobacterium sp. SKPB5 (MTCC 7803) and characterization of its alkaline protease. Curr Microbiol 2007, 54:224-229.

26. Zeng $\mathrm{R}$, Zhang $\mathrm{R}$, Zhao J, Lin $\mathrm{N}$ : Cold-active serine alkaline protease from the psychrophilic bacterium Pseudomonas strain DY-A: enzyme purification and characterization. Extremophiles 2003, 7:335-337.

27. Reddy LVA, Wee Y, Yun J, Ryu H: Optimization of alkaline protease production by batch culture of Bacillus sp. RKY3 through PlackettBurman and response surface methodological approaches. Biores Technol 2008, 99:2242-2249.

28. Anbu P, Annadurai G, Lee J-F, Hur B-K: Optimization of alkaline protease production from Shewanella oneidensis MR-1 by response surface methodology. J Chem Technol Biotechnol 2009, 84:54-62.
29. Rao YK, LU S, Liu B, Tzeng Y: Enhanced production of an extracellular protease from Beauveria bassiana by optimization of cultivation processes. Biochem Eng J 2006, 28:57-66.

30. Banerjee CU, Sani RK, Azmi W, Soni R: Thermostable alkaline protease from Bacillus brevis and its characterization as a laundry detergent additive. Process Biochem 1999, 35:213-219.

31. Joo HS, Kumar CG, Park GC, Kim KT, Paik SR, Chang CS: Optimization of the production of an extra cellular alkaline protease from Bacillus horikoshii. Process Biochem 2002, 38:155-159.

32. Kanekar PP, Nilegaonkar SS, Sarnaik SS, Kelkar AS: Optimization of protease activity of alkaliphilic bacteria isolated from an alkaline lake in India. Biores Technol 2002, 85:87-93.

doi:10.1186/1475-2859-10-114

Cite this article as: Singh et al.: Comparative one-factor-at-a-time, response surface (statistical) and bench-scale bioreactor level optimization of thermoalkaline protease production from a psychrotrophic Pseudomonas putida SKG-1 isolate. Microbial Cell Factories 2011 10:114.

\section{Submit your next manuscript to BioMed Central and take full advantage of:}

- Convenient online submission

- Thorough peer review

- No space constraints or color figure charges

- Immediate publication on acceptance

- Inclusion in PubMed, CAS, Scopus and Google Scholar

- Research which is freely available for redistribution 